УДК550.3, 550.31, 550.46

\title{
ГАЗОГИДРАТЫ АЗЕРБАЙДЖАНСКОГО СЕКТОРА ЮЖНОГО КАСПИЯ: ТЕРМОДИНАМИКА, СЕЙСМОАКУСТИКА И ГАЗОПРОЯВЛЕНИЯ
}

\author{
Полетаев Александр Владимирович', \\ avo1@mail.ru \\ Полетаева Елена Владимировна', \\ yelenapv@mail.ru \\ 1 Национальая Академия Наук Азербайджана, \\ Азербайджан, AZ1000, г. Баку, ул. Ф. Амирова, 9.
}

Актуальность. Геологическое строение и батиметрия морского дна глубоководной части Каспийского моря указывают на возможность образования значительных объемов газогидратов. Анализ опубликованных и неопубликованных материалов по газогидратам Каспийского моря показал, что в основном все работы базируются лишь на изучении скопления газогидратов Элм, Боздаг, площади Абшерон, а также термодинамических факторах региона (без учета реальных значений температуры и давления) с целью определения возможной зоны их скопления.

Цель исследования заключается в подсчете объема углеводородных газов газогидратов по термодинамическим данным, а также в изучении и прогнозировании их поступления в верхнюю часть разреза.

объектом исследования являются отложения верхней части разреза. Несмотря на большой фактический материал, имеющийся в различных организациях, верхняя часть разреза в связи с оценкой газоносности является наименее изученной и описанной в литературе зоной. Это связано с тем, что основной интервал исследований в Южном Каспии сосредоточен в участках с высоким потенциалом нефти и газа. Этим интервалом является продуктивная толща и подстилающие отложения, вошедшие в зону интенсивной генерации нефти и газа. Более молодые отложения, накопившиеся до абшеронского региояруса, в подавляющем случае состоящие из глинистых осадков, не представляли интереса. Во многих работах эта зона описывается как нерасчлененная толща четвертичных отложений

Методы исследования основаны на моделировании термодинамического равновесия углеводородных газов с целью установления зоны формирования газогидратов. В работе использованы данные температур и давления, замеренные в скважинах Южного Каспия, а также данные 160 сейсмоакустических профилей, разрезы интервальных скоростей и данные по нефтегазопроявлениям в пределах шельфовой зоны Южного Каспия.

В результате исследования термодинамического равновесия рассчитаны объемы зон газогидратов. Исходя из расчетов установлено, что суммарные объемы газа для изучаемой площади отложений составляют 1,15·10 ${ }^{13}$ газа. В результате интерпретации сейсмоакустических данных установлено, что интенсивность проявлений газа изменяется как по площади, так и сглубиной. В зонах, прилегающих к глубоководной части Южного Каспия, присутствие аномалий, характерных для газовых зон, увеличивается по сравнению с прибортовыми зонами. В результате анализа данных по газопроявлениям можно прийти к выводу, что верхняя часть разреза Южного Каспия сильно обогащена газом, причем интенсивность газопроявлений в нижней части наиболее высокая. Нефтепроявления на структурах Хали, Чилов адасы, Палчыг Пильпиля, Чираг указывают на то, что эти структуры более благоприятны для поисков нефтяных залежей. Пластовая вода зафиксирована в широком интервале глубин. Полученные выводы дают основание прогнозировать поступление значительных объемов флюидов в верхнюю часть разреза глубоководной части Южного Каспия.

Ключевые слова:

Газогидраты, сейсмоакустические профиля, оценка, газ, Южный Каспий, нефтегазовые месторождения.

\section{Введение}

Теоретические основы формирования газогидратов опубликованы в статьях и монографиях разных авторов [1-3 и др.], а использование этих основ и результатов приведено в публикациях [4-24]. Газогидраты - твердые кристаллические вещества, так называемые газовые клатраты. Кристаллическая решетка клатратов построена из молекул воды, во внутренних полостях которых размещены молекулы газа, образующего гидрат. Известны три основные структуры газогидратов: I, II и Н $[1,3]$. Процессы образования газовых гидратов начинаются с формирования центров кристаллизации на поверхности раздела газ-вода. Это может быть свободная плоская поверхность, поверхность микропузырька газа в объеме воды, поверхности капли и пленки воды сконденсировавшихся в объеме газа. Наиболее распространены массивные кристаллы газовых гидратов. Они формируются путем последовательной сорбции молекул газа и воды на растущей поверхности кристалла [25]. Морфологически выделено четыре основных вида газогидратов: мелковкрапленные, узловатые, слоистые, массивные. В петрографическом смысле в качестве породообразующего компонента газогидраты подразделяются на три типа: 1) гидрат - мономинеральная порода; 2) гидрат - главный породообразующий компонент (минерал); 3) гидрат акцессорный [26].

В результате расхождения в значениях физических параметров, необходимых для образования газогидратов из отдельных компонентов газа, происходит фракционирование состава многокомпонентных природных газов как в гидратах, так и в остаточном свободном газе в зоне возможного гидратообразования. [27]. Начало процесса образования газовых гидратов определяется составом газа, состоянием воды, внешним давлением и темпера- 
турой. Зависимость между давлением и температурой образования гидратов обычно изображается диаграммой гетерогенного состояния в координатах давления и температуры (РТ) [2, 3, 28, 29]. Впервые диаграмма гетерогенного равновесия была построена Г. Розебумом для гидрата хлора [1]. Ряд исследователей использовали эту диаграмму для описания зависимости равновесных условий образования гидратов газов в области умеренных давлений $[2,3,30]$. В дальнейшем, по мере развития исследований, появились более уточненные диаграммы, теоретические выкладки и т. д. В настоящее время существует несколько методов определения давления и температуры начала гидратообразования: а) графический; б) аналитический; в) графоаналитический; г) экспериментальный [4]. Для получения ориентировочных данных при определении условий начала образования гидратов используется графический метод. Рассмотрим основные виды диаграмм РТ равновесия, изучим температуру и давление, необходимые для формирования газогидратов для разных компонентов, используемые разными авторами при изучении газогидратосодержащих регионов. Авторы [31] обобщили данные и провели статистические исследования химического и изотопного состава газов в 26 газогидратосодержащих областях из 21 географического региона. В результате установлено, что метан является самым распространенным компонентом, причем углекислый газ $\left(\mathrm{CO}_{2}\right)$ и сумма тяжелых углеводородов $\left(\mathrm{C}_{2+}\right)$ в газогидрате по частоте представлены в меньших объемах [31]. В связи с этим подробно рассмотрим формирование газогидратов в системе РТ для метана. В [32] приведены равновесные параметры для индивидуальных газов, при этом экспериментальные данные разных авторов были сглажены, проинтерполированы и приведены к стандартным значениям температур: $263,15\left(-10{ }^{\circ} \mathrm{C}\right)$; $268,15\left(-5{ }^{\circ} \mathrm{C}\right) ; 273,15\left(0{ }^{\circ} \mathrm{C}\right) ; 278,15\left(5{ }^{\circ} \mathrm{C}\right) ; 283,15$ $\left(10{ }^{\circ} \mathrm{C}\right)$ К. В графической форме условия разложения газогидратов приведены для двух-, трехфазные равновесий. Для отдельных, наиболее распространенных, компонентов метана, этана, пропана используются равновесные кривые [32].

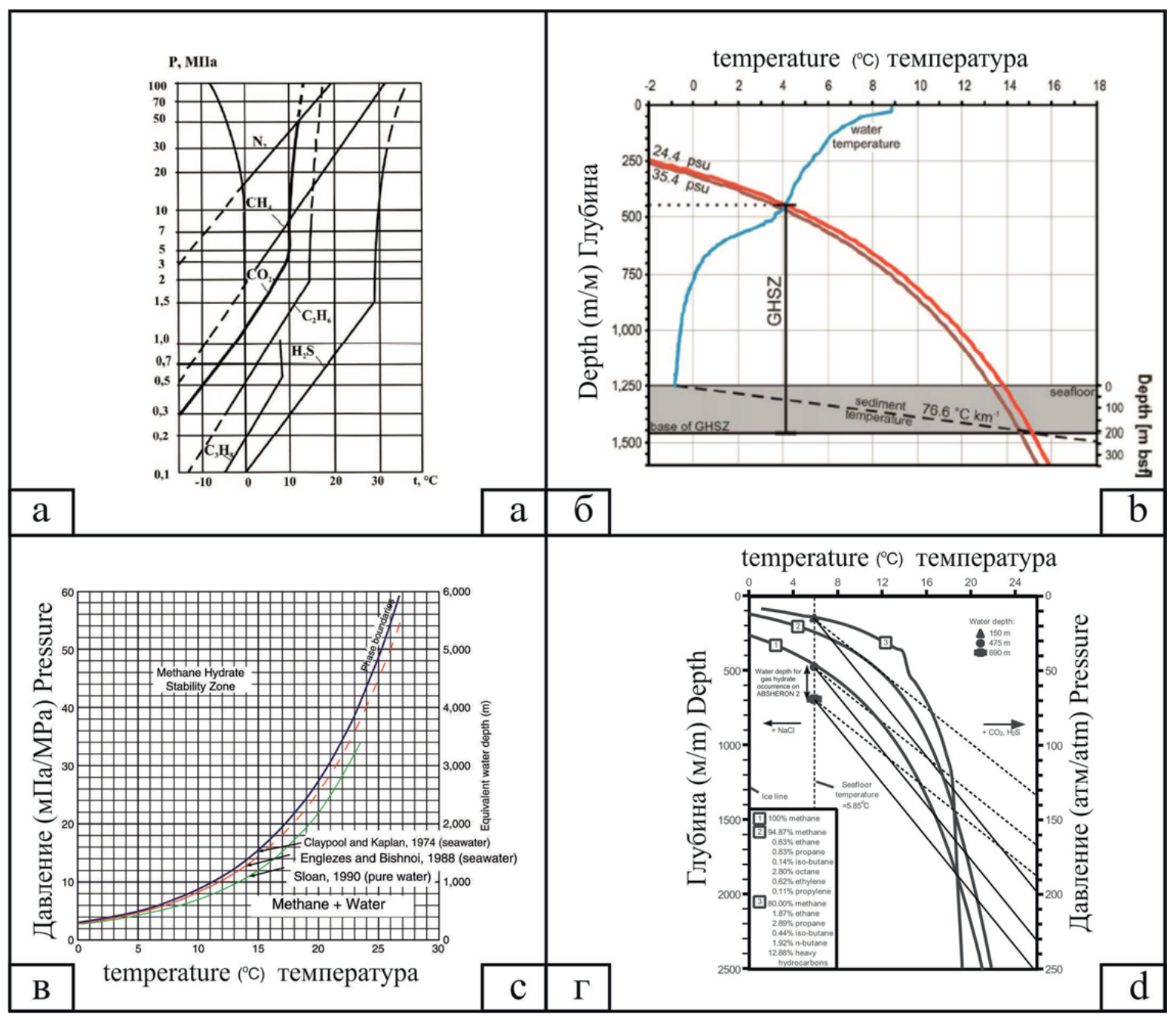

Рис. 1. Диаграммы гетерогенного состояния индивидуальных газов $(a, 6,8, г)$ в координатах давления и температуры

Fig. 1. Diagrams of the heterogeneous state of individual gases in the coordinates of pressure and temperature $(a, b, c, d)$ 
В работе [33] приведена диаграмма РТ равновесия, разработанная (Н. Katzet et al.) в 1959 г. и дополненная (К. Kvenvolden, M.Mc Menamin) в 1980 г. В ней приведена фазовая граница, располагающаяся в интервале глубин от 180 до $1600 \mathrm{M}$, охватывающая интервал температур от -20 до $+17{ }^{\circ} \mathrm{C}$. Для изучаемой области авторы нанесли на диаграмму кривые геотермического градиента.

Подробный обзор диаграмм приведен в монографиях [1, 4]. В работе представлена диаграмма (рис. $1, a$ ), разработанная для многокомпонентных фазовых сред. На диаграмме приведены кривые для метана, этана, пропана, бутана и изобутана, которые соответствуют интервалу температур от $-5,5$ до $+29,85{ }^{\circ} \mathrm{C}$ в интервале давлений от 0,1 до 80 мПа. Причем максимальная температура формирования газогидрата для метана составляет $29,85{ }^{\circ} \mathrm{C}$ при 80 мПа, для этана $-14,85{ }^{\circ} \mathrm{C}$ в интервале давлений от 2 до 8 мПа, а для пропана и изобутана максимальная температура составляет менее $4,85^{\circ} \mathrm{C}$

В работе [34] приведена зависимость температуры и глубины для метана. Авторы указывают на то, что граница BSR может отмечаться на глубине 250 м. По расчетным данным установлено, что формирование газогидратов может происходить в интервале глубин от 200 до 7000 м и охватывать температуры от -5 до $+29{ }^{\circ} \mathrm{C}$. Автор также указывает, что ниже и выше границы BSR наблюдается зона со свободным газом, причем в верхней части разреза концентрация газа биогенного формирования намного меньше, чем под зоной BSR.

B [35] приведены данные термодинамической стабильности формирования газогидратов (рис. 1, б). Авторы приводят границу газогидратов в интервале температур от 0 до $12{ }^{\circ} \mathrm{C}$ на глубинах от 200 до 1100 м. Кроме зон возможного скопления газогидратов на этой диаграмме указаны зоны свободного газа.

Кривая устойчивости для газогидратов [36], которая представляет собой соотношение Слоана, построена при наличии метана $-97,4 \%$ и сероводорода $-2,6 \%$ в газовой фразе и скорректирована по солености морской воды $(\mathrm{Cl}=555$ моль $)$. На диаграмме зона газогидратов располагается в интервале температур от 0 до $12{ }^{\circ} \mathrm{C}$ и соответствует интервалу глубин от 0 до 1100 м.

В монографии [28] приведена оценочная кривая фазового равновесия (К. Kvenvolden, 1998). Кривая располагается на глубинах от 150 до 5000 м и соответствует интервалу температур от -10 до $32{ }^{\circ} \mathrm{C}$, причем граница температуры воды соответствует интервалу от -2 до $0{ }^{\circ} \mathrm{C}$. Кривые Claypool and Kaplan (1974) рассчитаны (рис. 1, в) в интервале давлений от 0 до 60 мПа, что соответствует 0-690 бар (69 мПа), и располагаются в интервале температур 0 до $27{ }^{\circ} \mathrm{C}$. Кривые других авторов [28] колеблются приблизительно в тех же пределах, что и кривые Claypool and Kaplan (1974). Однако кривая Claypool and Kaplan (1974) рассчитана при солености воды $3,5 \%$.
В работе [29] приведена диаграмма стабильной зоны газогидратов для Северо-восточной части Аляски. На этой диаграмме приведена кривая для метана, которая соответствует интервалу температур от -5 до $+22{ }^{\circ} \mathrm{C}$ и диапазону глубин от 250 до 1400 м. На глубине 1800 м указана зона многолетней мерзлоты. Указанные кривые термодинамического равновесия составлены для метана. Однако существуют также кривые, построенные для этана, пропана, бутана и изобутана, сероводорода и других газов. Для каждой кривой имеются графики, которым соответствует индивидуальная температура. Максимальная температура установлена для сероводорода и составляет $26,85{ }^{\circ} \mathrm{C}$. Созданы и другие графики стабильности газогидратов [30], согласно которым температура колеблется 12 до $18{ }^{\circ} \mathrm{C}$ в интервале глубин до $600 \mathrm{~m}$.

Для территории Азербайджана авторы используют кривые разных авторов [1-3, 30]. Так, в работе [30] приведена РТ диаграмма, охватывающая интервалы температур от -10 до $+30{ }^{\circ} \mathrm{C}$, в интервале давлений от 0 до 6 мПа. Учитывая геотермические данные и равновесные параметры гидратообразования, полученные по результатам измерений в герметичных контейнерах, автор [30] предполагает, что гидратоносная зона находится в пределах первых десятков метров ниже уровня морского дна. По сравнению с Буздагом на вулкане Элм эта зона несколько больше, так как здесь глубина моря превышает таковую почти на 200 м.

В работе [37] приведена диаграмма термодинамического равновесия (рис. 1, г). На этой диаграмме в интервале глубин 0 до 2500 м в диапазоне температур от 0 до $20{ }^{\circ} \mathrm{C}$ устанавливается кривая по метану. Авторы статьи [37] из различных уравнений, разработанных для газогидрата, использовали исследование трехфазного равновесия [3, 38].

Другим важным фактором при формировании газогидратов является поступление в зону гидратообразования значительного количества газа. В связи с этим основной целью данной части работы является определение, уточнение и детализация основных источников газа, имеющихся в верхней части разреза шельфовой зоны, с использованием геофизического материала и данных по газонефтепроявлениям. С целью изучения зон газогидратов и прогнозирования нефтегазоносности четвертичных отложений глубоководной части азербайджанского сектора Южного Каспия появилась необходимость в обобщении существующих данных по сопредельным зонам бакинского и абшеронского нефтегазоносных районов, что позволило бы более обоснованно подойти к исследованиям неразбуренной глубоководной части Южного Каспия. Акустические исследования в пределах Южного Каспия начали проводиться с 1956 г. С того времени опубликовано небольшое количество статей на эту тему [39, 40 и др.]. Несмотря на большой фактический материал, имеющийся в различных организациях, верхняя часть разреза в связи с оценкой газоносности является наименее 
изученной и описанной в литературе зоной. Это связано с тем, что основной интервал исследований в Южном Каспии сосредоточен в участках с высоким потенциалом нефти и газа $[41,42]$. Этим интервалом является продуктивная толща и подстилающие отложения, вошедшие в зону интенсивной генерации нефти и газа. Более молодые отложения, накопившиеся до абшеронского региояруса, в подавляющем случае состоящие из глинистых осадков, не представляли интереса. Во многих работах эта зона описывается как нерасчлененная толща четвертичных отложений [43].

\section{Методика и фактический материал}

В работе использованы данные температур [44], замеренные в скважинах Южного Каспия. При выполнении исследований проведены работы по сортировке температур и давлений изучаемой территории. Сортировка данных производилась с целью установления глубины залегания отложений с температурой $24{ }^{\circ} \mathrm{C}$, а также для изучения диапазона изменения давлений в верхней части разреза (ВЧР). Полученный объем данных (рис. 2, 3) позволил проанализировать общую тенденцию изменения температуры по площади.

Для изучения возможных интервалов температур формирования скоплений газогидратов в пределах Азербайджанского сектора Южного Каспия использована методика [2]. Метод является универсальным для определения формирования газогидратов и дает возможность рассчитать температуру формирования газогидрата, образованного для различных типов гидратов. Методические основы моделирования процессов гидратообразова- ния реализованы в программном комплексе «Gashydrate plus».

В общей сложности использовано 160 сейсмоакустических профилей, а по разным площадям от 3 до 8 профилей (табл. 1, рис. 4). Для изучения наличия и поступления газа в верхнюю часть разреза произведена интерпретация сеймоакустических данных по методике [28, 45].

Газонефтепроявления изучены по скважинным данным 21 месторождения (рис. 4, 9). Построены сводные колонки нефтегазопроявлений для указанных месторождений Южного Каспия. Следует отметить, что номера колонок на рис. 6 соответствуют номерам на карте (рис. 1).

\section{Результаты исследований}

\section{по термодинамическим данным}

На рис. 2 пунктирными линиями указаны данные распределения температур, которые восстановлены из анализа и сопоставления геологических структур и теплого поля в пределах изучаемых зон, а также подтверждены расчетными данными. Сплошными линиями показаны результаты интерполяции фактических данных. Анализ карты указывает, что температура в $24{ }^{\circ} \mathrm{C}$ в пределах Южного Каспия отмечается в интервале глубин от 280 до 480 м. Таким образом, анализ распределения температур в пределах Южного Каспия указывает, что максимальная глубина формирования газогидратов по метану может соответствовать глубине 480 м. Пластовое давление изучено на площадях Пираллахи, Нефт Дашлары, Гюнешли, Чираг, Азери. На площади Пирралахи на глубине 417 м в скважине 72 пластовое давление составля-

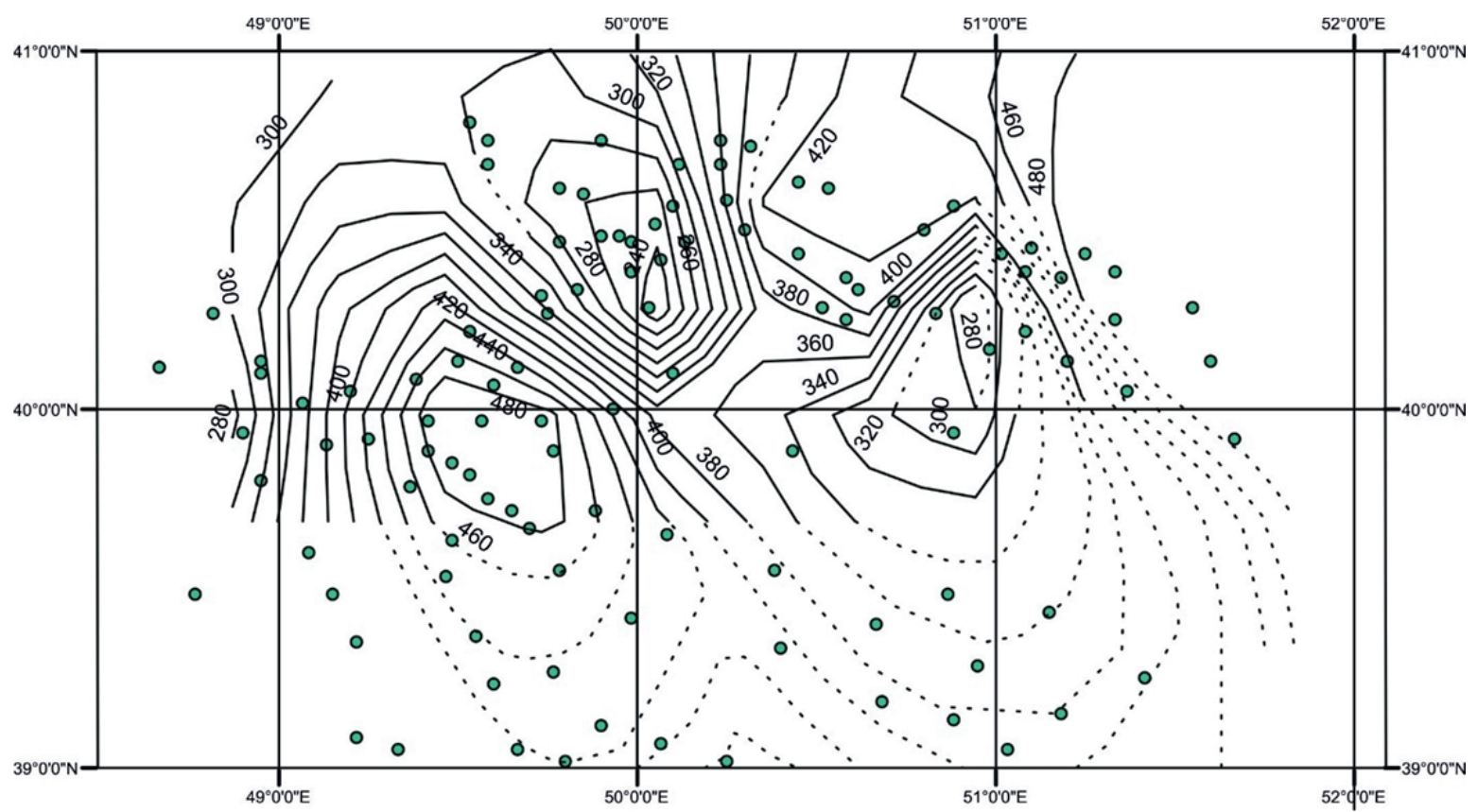

Рис. 2. Карта изменения глубины при фиксированной температуре 24 градуса

Fig. 2. Depth change map at fixed temperature of 24 degrees 
ет 22 мПа $(217,111$ атм), а на 560 м - 38 мПа (375,011 атм). В скважине 355 на глубине $416 \mathrm{м}$ пластовое давление составляет 10 мПа $(98,687$ атм), а в скважине 456 пластовое давление равно 18 мПа $(177,637$ атм). Подобное изменение пластового давления наблюдается и по другим месторождениям и площадям. Анализ пластовых давлений по площади ВЧР указывает на колебание значений от $0,3 \mathrm{м \Pi а}(2,96061$ атм $)$ до $38 \mathrm{м \Pi а}$ (375,011 атм).

Таблица 1. Объем сейсмоакустического материала

Table 1. Volume of seismoacoustic material

\begin{tabular}{|c|c|c|c|}
\hline $\begin{array}{l}\text { Месторождение } \\
\text { Field }\end{array}$ & $\begin{array}{c}\text { Кол-во } \\
\text { профилей } \\
\text { Number } \\
\text { of profiles }\end{array}$ & $\begin{array}{l}\text { Месторождение } \\
\text { Field }\end{array}$ & $\begin{array}{c}\text { Кол-во } \\
\text { профилей } \\
\text { Number } \\
\text { of profiles }\end{array}$ \\
\hline Пираллахи/Pirallakhi & 4 & Сабаил/Sabail & 5 \\
\hline Гум-дениз/Gum-deniz & 9 & $\begin{array}{l}\text { Бяндован-дениз } \\
\text { Byandovan-deniz }\end{array}$ & 2 \\
\hline Хали/Khali & 5 & Инам/Inam & 6 \\
\hline \begin{tabular}{|l|} 
Нефт Дашлары \\
Neft-Dashlary
\end{tabular} & 10 & $\begin{array}{l}\text { Абшеронбанкасы } \\
\text { Absheronbankasy }\end{array}$ & 3 \\
\hline Гюнешли/Gyuneshli & 4 & Apзy/Arzu & 4 \\
\hline Чираг/Chirag & 28 & Дан улдузу/Dan ulduzu & 3 \\
\hline Кяпаз/Куараz & 6 & Айпара/Aypara & 3 \\
\hline Бахар/Bakhar & 6 & Ашрафи/Ashrafi & 4 \\
\hline $\begin{array}{l}\text { Шах-дениз } \\
\text { Shakh-deniz }\end{array}$ & 18 & \multirow{5}{*}{$\begin{array}{l}\text { Региональный профиль } \\
\text { (глубоководная часть } \\
\text { Южного Каспия) } \\
\text { Regional profile } \\
\text { (deep-water of the } \\
\text { South Caspian) }\end{array}$} & \multirow{5}{*}{4} \\
\hline $\begin{array}{l}\text { Ширван-дениз } \\
\text { Shirvan-deniz }\end{array}$ & 6 & & \\
\hline Хара-Зиря/Khara-Zirya & 7 & & \\
\hline Булладениз/Bulla-deniz & 8 & & \\
\hline Умид/Umid & 6 & & \\
\hline Бабек/Babek & 9 & Сумmа/Total & 160 \\
\hline
\end{tabular}

Расчеты термодинамического моделирования указали на возможность формирования газогидратов в пределах установленной зоны. На основе программного комплекса «Гидрат+» рассчитаны температура и давление, благоприятные для образования кристаллогидратов. За основу расчетов взяты анализы газов кристаллогидратов, отобранных на грязевых вулканах Боздаг и Элм. В табл. 2, 3 показаны расчетные температуры и давления, при которых образуются кристаллогидраты в условиях Южного Каспия. В табл. 2 рассмотрен состав газа кристаллогидратов Боздаг. Аналогичные данные были получены для химического состава кристаллогидратов на грязевом вулкане Элм (табл. 3). Из табл. 3 следует, что изменение температур на газогидратном скоплении Элм является аналогичным с таковым на Боздаге и варьируют в пределах от 1,62 до $24,16^{\circ} \mathrm{C}$. Данные расчеты были осуществлены для толщи морской воды.

Применение этих данных вместе с данными «Геотермальный атлас Азербайджана» [44], отчетами Института Геологии и Геофизики, а также первичными данными, полученными Государственной Нефтяной Компанией Азербайджанской
Республики, позволило проанализировать общую тенденцию изменения пластовой температуры в зависимости от глубины ниже данного слоя моря. Давление на глубинах воды 10, 100, 1000 м составляет 1 (0,10133 мПа), 10 (1,0133 мПа), 100 атм (10,133 мПа) соответственно, т. е. давление на каждые 10 м увеличивается на 1 атм $(0,10133$ мПа).

По приведенным данным пластовая температура на глубине 500 м изменяется от 23,0 до $27,8{ }^{\circ} \mathrm{C}$, в среднем составляя $24,6{ }^{\circ} \mathrm{C}$, что соответствует возможности образования кристаллогидратов. В связи с этим температура и давление изменяются по площади и разрезу, термодинамическое равновесие нарушается, что выражается в неравномерном распределении зон газогидратов как по площади, так и по разрезу.

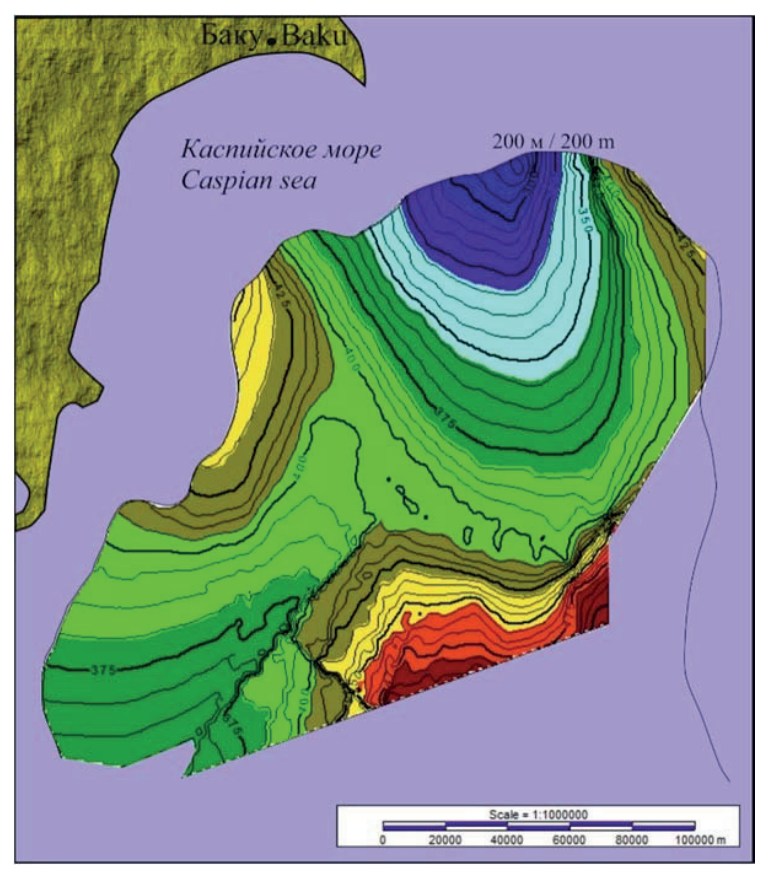

Рис. 3. Карта изменения глубины при фиксированной температуре $24{ }^{\circ} \mathrm{C}$ (глубоководная часть Южного Каспия)

Fig. 3. Map of depth change at fixed temperature of $24{ }^{\circ} \mathrm{C}$ (deep-water part of the South Caspian)

\section{Результаты исследования по сейсмоакустическим данным и газонефтепроявлениям}

На сейсмоакустических профилях установлены зоны с грязевулканическими структурами, а также многочисленные выходы газа, газовые факелы. Газовые факелы прослеживаются на месторождениях Умид, Сабаил, Кяпаз, Нефт Дашлары и др. Проявление газа в виде газовых факелов является не единственным критерием оценки наличия газа. На профилях установлены характерные для газа вертикальные столбы хаотической записи волн, а также аномалии, свойственные для зон газа. Следует отметить, что фактически вся площадь Южного Каспия, в особенности верхняя ее часть, является интенсивной зоной аккумуляции и дегазации газов. Максимальный интервал интерпрета- 
ции составляет 400 м. В зависимости от территориальной принадлежности площадей наблюдаются определенные изменения и в волновом поле. Чередование песчанисто-глинистых отложений на месторождении Нефт Дашлары имеет более выраженную волновую картину по сравнению с месторождением Гум-адасы. Более интенсивные выходы газа зафиксированы в зонах грязевулканических проявлений, на месторождениях Кяпаз, Шах-дениз и др.

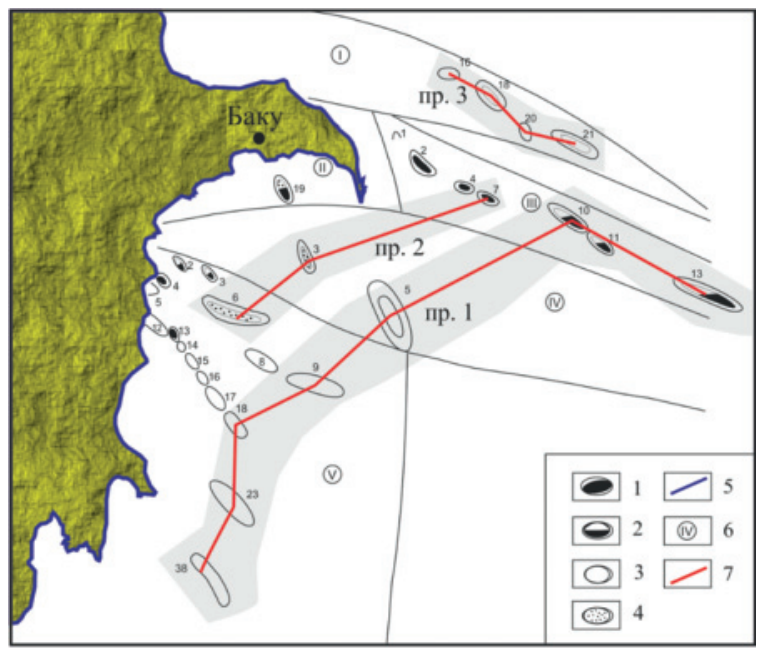

Рис. 4. Расположение основных групп сейсмоакустических профилей (в основу положена карта тектонического районирования нефтегазоносных территорий Азербайджана [41]). Условные обозначения: 1- нефтяные месторождения, 2 - нефтегазовые месторождения, 3 - газовые месторождения, 4 - нефтегазоконденсатные месторождения, 5 - берег моря, 6 -номер района, 7 - линия профиля. I-16. Арзу, 18. Дан улдузу, 20. Айпара, 21. Ашрафи; II - 19. Гум-дениз; III - 1. Хали, 2. Чиловадасы, 4. Палчыг Пилпилясы, 7. Нефт Дашлары, 10. Гюнешли, 11. Чираг, 13. Кяпаз; IV - 3. Бахар, 5. Шах-дениз; V - 2. Дуванный-дениз, 3. ХараЗиря, 4. Алят-дениз, 5. Гиладасы, 6. Булла-дениз, 8. Умид, 9. Бабек (Д-1), 12. Хамамдаг-дениз, 13. Гарасу, 14. Санги Мугань, 15. Ульфат, 16. Аран-дениз, 17. Дашлы, 18. Сабаил, 23. Ширван-дениз, 38. Инам

Fig. 4. Location of the main groups of seismoacoustic profiles (based on the tectonic zoning of oil and gas areas of Azerbaijan) [41]. Legend: 1 are the oilfields, 2 are the oilgas fields, 3 are the gasfields, 4 are the oil-gas condensate fields, 5 is the sea shore, 6 is the number of region, 7 is the cross-section line. I-16. Arzu, 18. Dan ulduzu 20. Aypara, 21. Ashrafi; II - 19. Gum deniz; III - 1. Khali, 2. Chilov adasi, 4. Palchig Pilpilyasi, 7. Neft Dashlari, 10. Guneshli, 11. Chirag, 13. Kapaz; IV - 3. Bakhar, 5. Shakh-deniz; V - 2. Duvanniy-deniz, 3. Khara-Zirya, 4. Alyat, 5. Gil adasi, 6. Bulla-deniz, 8. Umid, 9. Babek (D-1), 12. Khamamdag-deniz, 13. Garasu, 14. Sangi-Mugan, 15. Ulfat, 16. Aran-deniz, 17. Dashli, 18. Sabail, 23. Shirvan-deniz, 38. Inam

Рассматривая изменения волновой картины по площади, можно прийти к выводу, что поступление газа в ВЧР связано не только с наличием грязевулканических структур и зон разломов, но и с вертикальной разгрузкой флюидов. Это позволяет говорить о поступлении газа из нефтегазовых структур в верхнюю часть разреза. Очевидно, что наличие мощной глинистой толщи в верхней части разреза не является идеальным изолирующим фактором.

C целью детального анализа изменения газоносности отложений как по площади, так и по разрезу изучены сейсмоакустические профили (табл. 1). Имеющийся объем сейсмоакустических данных условно был разбит на три группы (линии профилей). $\mathrm{K}$ первой группе относятся профили (рис. 5), примыкающие к глубоководной части Южного Каспия. Во вторую группу профилей (рис. 6), условно названную промежуточной зоной, входят месторождения Булла-дениз-Бахар-Нефт Дашлары, а третья группа (линия) включает зону Ашрафи-Айпара-Дан улдузу-Арзу (рис. 7).

1. Инам-Ширван-дениз-Сабаил-Бабек-Шах-дениз-Гюнешли-Кяпаз.

2. Булла-дениз-Бахар-Нефт Дашлары.

3. Ашрафи-Айпара-Дан улдузу-Арзу.

Таблица 2. Моделирование термодинамического равновесия газогидратного скопления Боздаг

Table 2. Modeling thermodynamic equilibrium of Bozdag gas hydrate accumulation

\begin{tabular}{|c|c|c|c|c|c|c|c|c|c|c|}
\hline № & $C_{1}$ & $C_{2}$ & $C_{3}$ & $\mathrm{iC}_{4}$ & $\mathrm{nC}_{4}$ & $C_{5}$ & $\mathrm{CO}_{2}$ & $\begin{array}{l}\text { Глубина } \\
\text { Depth }\end{array}$ & $\begin{array}{l}\text { P, атм/MПа } \\
P, \text { atm/MPa }\end{array}$ & $t,{ }^{\circ} \mathrm{C}$ \\
\hline 1 & \multirow{16}{*}{7,1} & & \multirow{10}{*}{2} & \multirow{16}{*}{0,4} & \multirow{11}{*}{1,1} & \multirow{16}{*}{0,33} & \multirow{16}{*}{0,45} & 150 & $15(1,51996)$ & 6,1695 \\
\hline 2 & & & & & & & & 200 & $20(2,02661)$ & 8,5317 \\
\hline 3 & & & & & & & & 250 & $25(2,53326)$ & 10,2670 \\
\hline 4 & & & & & & & & 300 & $30(3,03991)$ & 11,6980 \\
\hline 5 & & & & & & & & 350 & $35(3,54657)$ & 12,8830 \\
\hline 6 & & & & & & & & 400 & $40(4,05322)$ & 13,8730 \\
\hline 7 & & & & & & & & 450 & $45(4,55987)$ & 14,7030 \\
\hline 8 & & \multirow{3}{*}{ 18, } & & & & & & 500 & $50(5,06652)$ & 15,5020 \\
\hline 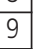 & & & & & & & & 550 & $55(5,57318)$ & $\mid 16,2740$ \\
\hline 10 & & & & & & & & 1050 & $105(10,6397)$ & 20,0850 \\
\hline 11 & & & & & & & & 1550 & $155(15,7062)$ & 21,7450 \\
\hline 12 & & & & & & & & 2050 & $205(20,7727)$ & 23,0740 \\
\hline 13 & & & & & & & & 2550 & $255(25,8393)$ & 24,0180 \\
\hline 14 & & & & & & & & 2600 & $260(26,3459)$ & 24,1150 \\
\hline 15 & & & & & & & & 2650 & $265(26,8526)$ & 24,2120 \\
\hline 16 & & & & & & & & 2700 & $270(27,3592)$ & 24,3100 \\
\hline
\end{tabular}

Таким образом, мы можем детально проанализировать изменения волновой картины по указанным профилям и по месторождениям в целом. Первый профиль охватывает зону Инам-Кяпаз. Геологическое строение структур по профилю неодинаковое. По сейсмоакустическим профилям можно уверенно проследить четкие отражающие горизонты, соответствующие отложениям четвертичного возраста. Геологическое строение этих месторождений хорошо описано в работах $[42,46$, 47]. Глинистые отложения являются подавляющими отложениями верхней части разреза. Однако для некоторых зон наблюдается и увеличенное содержание песчаного материала. Этот вывод базируется на данных бурения.

Как видно из рис. 5-7, максимальная газонасыщенность отложений устанавливается на про- 
филе 1 , на последующих профилях наблюдается постепенное уменьшение газонасыщенности отложений. Минимальные значения отмечаются на профиле 3.

Анализ скоростей [48] по профилям (рис. 8, $a-8$ ) показал, что скорости и, соответственно, петрофизические условия меняются по площади и разрезу. На разрезах установлены схожие между собой 30ны, выделенные характерным цветом. Выявленные интервалы (пунктирные линии) соответствуют зонам скоплениям флюидов (породам, сильно насыщенных газом). Этот вывод исходит из сопоставления данных, полученных во время бурения и изучения профилей. Особенности скоростной картины по различным профилям указывают на значительные объемы флюидов, которые могут заполнять верхнюю часть разреза. Пересечение профилей и интервалы глубин указывают на идентичность аномалий, формирующихся в единых стратиграфических зонах.

Таблица 3. Моделирование термодинамического равновесия газогидратного скопления Элм

Table 3. Modeling thermodynamic equilibrium of Elm gas hydrate accumulation

\begin{tabular}{|c|c|c|c|c|c|c|c|c|c|}
\hline № & $C_{1}$ & $C_{2}$ & $C_{3}$ & $\mathrm{iC}_{4}$ & $n C$ & $\mathrm{CO}_{2}$ & \begin{tabular}{|l|} 
Глубина \\
Depth
\end{tabular} & $\begin{array}{l}P \text {, атм (мПа) } \\
P, \text { atm (MPa) }\end{array}$ & $t_{1}{ }^{\circ} \mathrm{C}$ \\
\hline 1 & \multirow{16}{*}{81,4} & \multirow{16}{*}{15,3} & \multirow{16}{*}{1,6} & & & \multirow{16}{*}{0,81} & 150 & $15(1,51996)$ & 5,2995 \\
\hline 2 & & & & \multirow{15}{*}{0,2} & & & 200 & $20(2,02661)$ & 7,6785 \\
\hline 3 & & & & & & & 250 & $25(2,53326)$ & 9,4449 \\
\hline 4 & & & & & & & 300 & $30(3,03991)$ & 10,9070 \\
\hline 5 & & & & & & & 350 & $35(3,54657)$ & 12,1230 \\
\hline 6 & & & & & & & 400 & $40(4,05322)$ & 13,1430 \\
\hline 7 & & & & & & & 450 & $45(4,55987)$ & 14,0010 \\
\hline 8 & & & & & & & 500 & $50(5,06652)$ & 14,8280 \\
\hline 9 & & & & & & & 550 & $55(5,57318)$ & 15,6270 \\
\hline 10 & & & & & 0,7 & & 1050 & $105(10,6397)$ & 19,6480 \\
\hline 11 & & & & & & & 1550 & $155(15,7062)$ & 21,4350 \\
\hline 12 & & & & & & & 2050 & $205(20,7727)$ & 22,8520 \\
\hline 13 & & & & & & & 2550 & $255(25,8393)$ & 23,8570 \\
\hline 14 & & & & & & & 2600 & $260(26,3459)$ & 23,9600 \\
\hline 15 & & & & & & & 2650 & $265(26,8526)$ & 24,0620 \\
\hline 16 & & & & & & & 2700 & $270(27,3592)$ & 24,1640 \\
\hline
\end{tabular}

На рис. 9 разными условными обозначениями зафиксированы участки с выходами газа различной интенсивности, присутствием нефти, пластовой воды или запаха сероводорода. Все данные ранжированы по площади, что позволяет проследить изменения зафиксированных газонефтепроявлений как по площади, так и по разрезу в пределах установленных глубин. Как видно из рис. 9 , максимальная газонасыщенность отложений соответствует подстилающим отложениям. Сводный разрез указывает на то, что ВЧР преимущественно представлена глинистыми отложениями с прослоями песчаника небольшой мощности. В пределах исследуемой зоны наибольший интерес вызывает присутствие пластовой воды. Она наблюдается в интервале глубин от 0 до 200 м в Восточно-Абшеронском районе, в то время как в нефтегазоносном районе Бакинского архипелага ее наличие фиксируется в более широком интервале глубин от 0 до 2800 м. Следует отметить, что вода газирована. Величина пористости в верхней части разреза составляет $40 \%$. Вода была также зафиксирована на месторождении Чилов адасы, расположенном в Восточно-Абшеронском нефтегазоносном районе. Большой фактический материал по Бакинскому архипелагу позволяет наиболее детально охарактеризовать эту зону. Значительные объемы пластовой воды были установлены на месторождении Дуванный-дениз, Хара-Зиря, Алят-дениз, Санги-мугань, Дашлы. На месторождении Умид притоки воды были зафиксированы на более глубоких горизонтах - в интервале глубин от 240 до 2800 м. Газопроявления установлены практически на всех месторождениях за исключением Чираг, Гиладасы, Аран-дениз, Арзу. На двух площадях -Дашлы и Аран-дениз - зафиксировано присутствие $\mathrm{H}_{2} \mathrm{~S}$. На месторождении Аран-дениз наличие $\mathrm{H}_{2} \mathrm{~S}$ выявлено до глубин 100 м, в то время как на месторождении Дашлы- на глубине около 500 м. На структурах Хали, Чилов адасы, Палчыг Пильпиля, Чираг Восточно-Абшеронского нефтегазоносного района в верхней части разреза установлены нефтепроявления. Необходимо отметить, что месторождение Палчыг Пильпиля до глубин 600 м характеризуется более песчаными отложениями по сравнению с другими структурами Бакинского архипелага. Эта площадь в верхней части разреза наиболее насыщена нефтями. На месторождении Булладениз притоки пластовой воды зафиксированы в разных интервалах разреза от глубин 600 до 6310 м. В стратиграфическом плане они охватывают практически весь разрез. В апшеронском и акчагыльском региоярусах, а также верхах ПТ минерализация воды составляет от 49 до 129 г/л. Таким образом, можно уверенно прогнозировать поступления значительных объемов УВ газов в верхнюю часть разреза глубоководной зоны Южного Каспия. Комплексирование полученных данных по термодинамике с результатами, полученными при изучении газоносности верхней части разреза, позволило подсчитать максимальный объем газа из газогидратов для всей газогидратной зоны.

\section{Оценка объемов газогидратов}

C целью оценки объемов газов в зонах газогидратов (GH) была использована общепринятая формула:

$$
\mathrm{GH}=V \times \varnothing \times S_{h} \times F V,
$$

где $V$ - объем породы, определенный по данным термодинамических исследований; $\varnothing$ - средняя пористость в зоне газогидратов; $S_{h}$ - степень емкостного заполнения пористости газогидратов; $F V$ коэффициент расширения метана при разложении газогидрата (обычно принят как 160). Вводные и расчётные данные приведены в табл. 4.

Следует отметить, что средняя величина пористости в зоне газогидратов была занижена на 


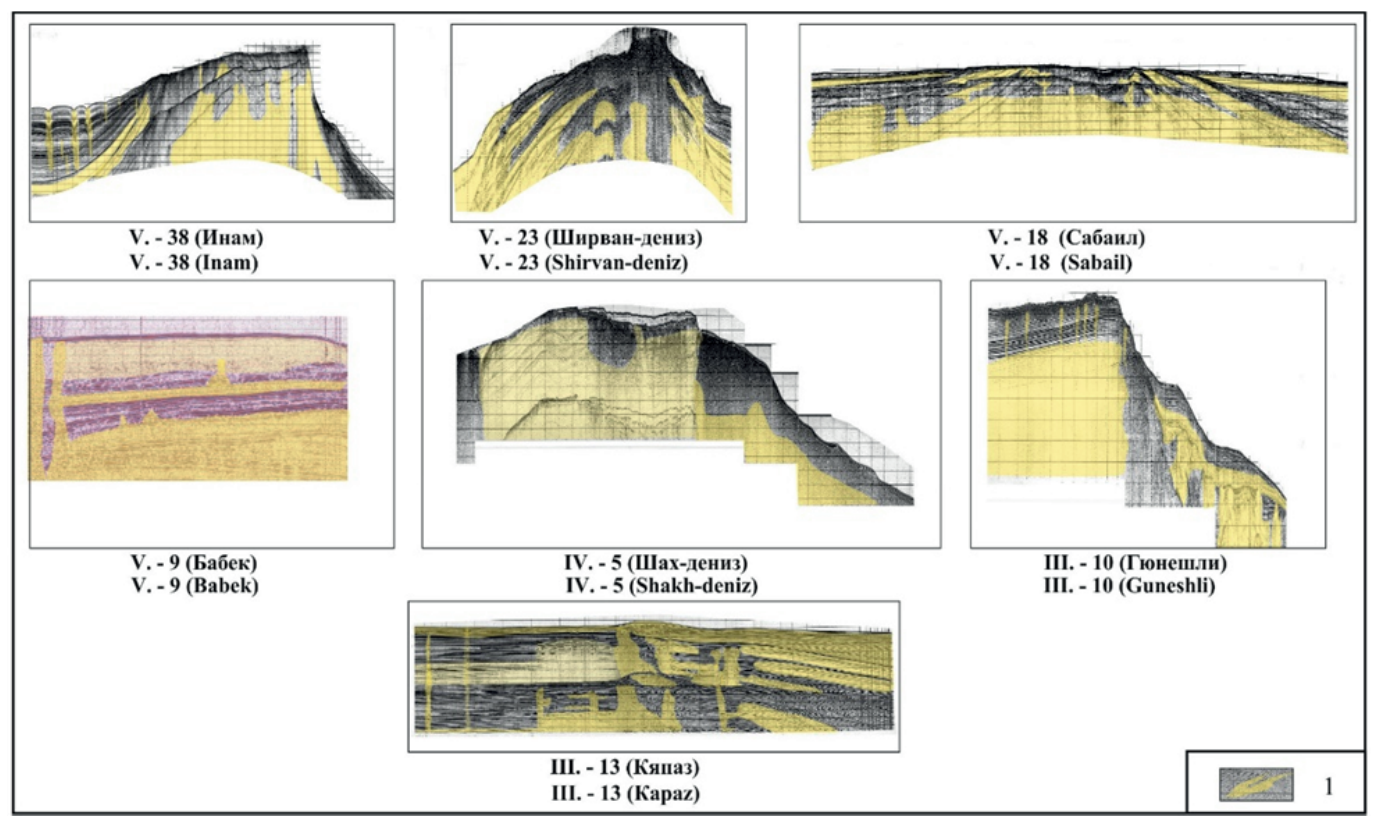

Рис. 5. Результаты интерпретации сейсмоакустических данных (по профилю 1). 1 - области аномалий, которые соответствуют газовым проявлениям

Fig. 5. Results of interpretation of seismoacoustic data (by profile 1). 1 are the areas of anomalies, corresponding to gas shows

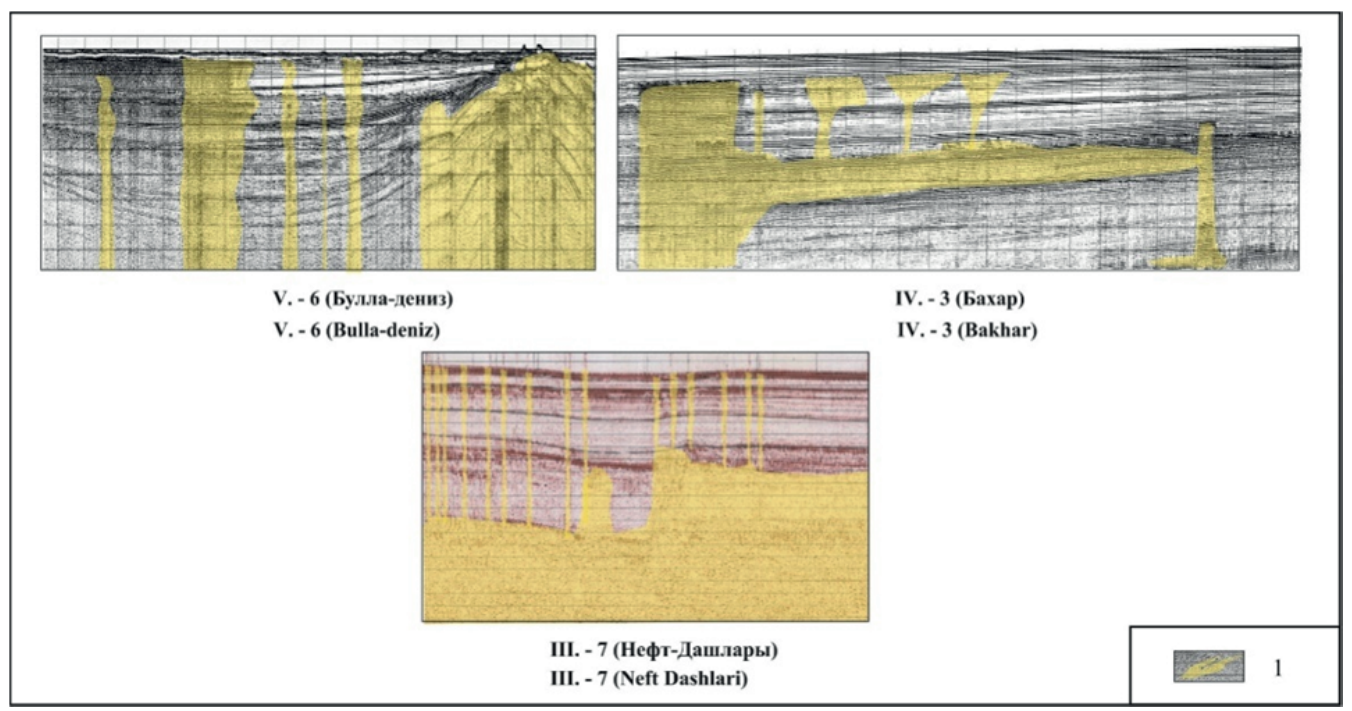

Рис. 6. Результаты интерпретации сейсмоакустических данных (по профилю 2). 1 - области аномалий, которые соответствуют газовым проявлениям

Fig. 6. Results of interpretation of seismoacoustic data (by profile 2). 1 are the areas of anomalies, corresponding to gas shows

Таблица 4. Расчеты объемов УВ газов в зонах газогидратов

Table 4. Calculations of hydrocarbon gas volumes within gas hydrate zones

\begin{tabular}{|c|c|c|c|c|c|}
\hline $\begin{array}{l}\text { Площадь ис- } \\
\text { следования } \\
\text { Area of study }\end{array}$ & $\begin{array}{c}\text { Объем породы, определен- } \\
\text { ный по данным сейсмических } \\
\text { методов исследований }(V) \\
\text { Volume of rock, determined by } \\
\text { seismic research methods }(V)\end{array}$ & $\begin{array}{c}\text { Средняя пори- } \\
\text { стость в зоне га- } \\
\text { зогидратов }(\varnothing) \\
\text { Average porosity } \\
\text { in the gas hydrate } \\
\text { zone }(\varnothing)\end{array}$ & $\begin{array}{c}\text { Степень емкостного за- } \\
\text { полнения пористости } \\
\text { газогидратов }\left(S_{h}\right) \\
\text { Degree of capacitive fil- } \\
\text { ling of porosity of gas } \\
\text { hydrates }\left(S_{h}\right)\end{array}$ & $\mid \begin{array}{c}\text { Коэффициент расширения } \\
\text { метана при разложении } \\
\text { газогидрата (FV) } \\
\text { Coefficient of methane ex- } \\
\text { pansion during decomposi- } \\
\text { tion of gas hydrate (FV) }\end{array}$ & $\begin{array}{l}\text { Объем газа (GH) } \\
\text { Gas volume (GH) }\end{array}$ \\
\hline $\begin{array}{l}\text { Общая } \\
\text { General }\end{array}$ & $9968864,727510^{6} \mathrm{M}^{3}$ & 0,20 & 0,036 & 160 & $1,15 \cdot 10^{13}$ \\
\hline
\end{tabular}




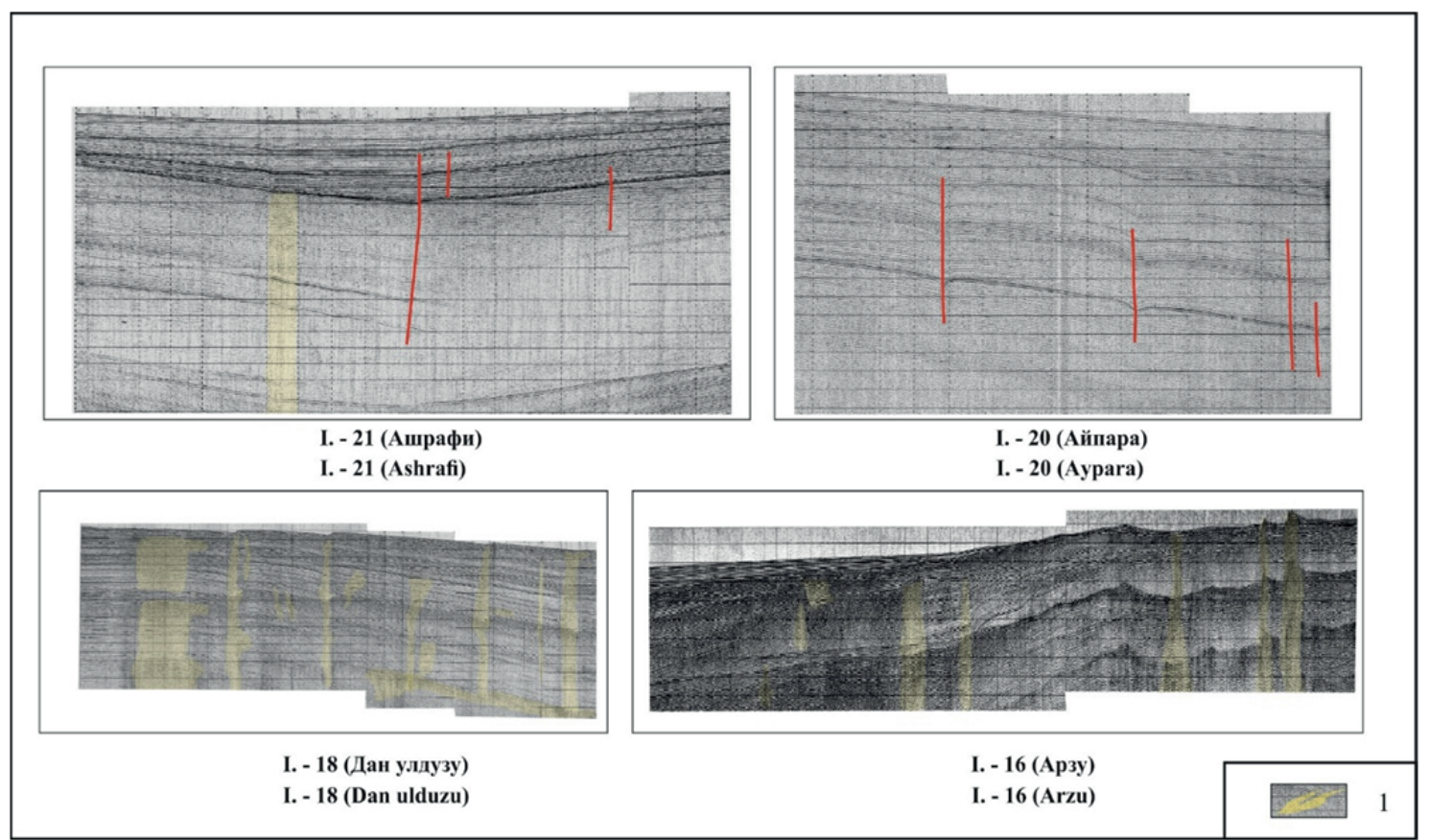

Рис. 7. Результаты интерпретации сейсмоакустических данных (по профилю 3). 1 -области аномалий, которые соответствуют газовым проявлениям

Fig. 7. Results of interpretation of seismoacoustic data (by profile 3). 1 are the areas of anomalies, corresponding to gas shows

$50 \%$, что позволит более обосновано подойти к изучению объемов УВ газа газогидратов. $S_{h}$ значения выбраны и использованы исходя из анализа результатов, полученных на двух скоплениях газогидратов Боздаг и Элм, а также из анализа данных [49-51]. Значение $S_{h}$ для глин составляет 0,036 .

Как видно из приведенных расчетов, суммарные объемы газа, рассчитанные для изучаемой площади отложений, составляют $1,15 \cdot 10^{13} \mathrm{M}^{3}$ газа. Справедливо отметить, что генерация газа по площади неодинаковая, что подтверждается и данными сейсмических исследований.

\section{Выводы}

Изучение методологических основ и опубликованных работ по газогидратам позволило провести анализ фазовых диаграмм гидратообразования. Анализ методических приемов интерпретации газогидратов показывает, что глубина их формирования изменяется в довольно широких пределах, но ограничена температурой в $24^{\circ} \mathrm{C}$. Рассмотрены фактические данные распределения температуры и давления в пределах Южного Каспия. Построена карта изменения глубины при фиксированной температуре $24{ }^{\circ} \mathrm{C}$. Рассчитано термодинамическое равновесие для газов двух газогидратных скоплений - Боздаг и Элм. Скопления кристаллогидратов в акватории Южного Каспия характеризуются неравномерным распределением в породах. Положение их определяется неоднородностью температурного поля и давления по площади и разрезу.

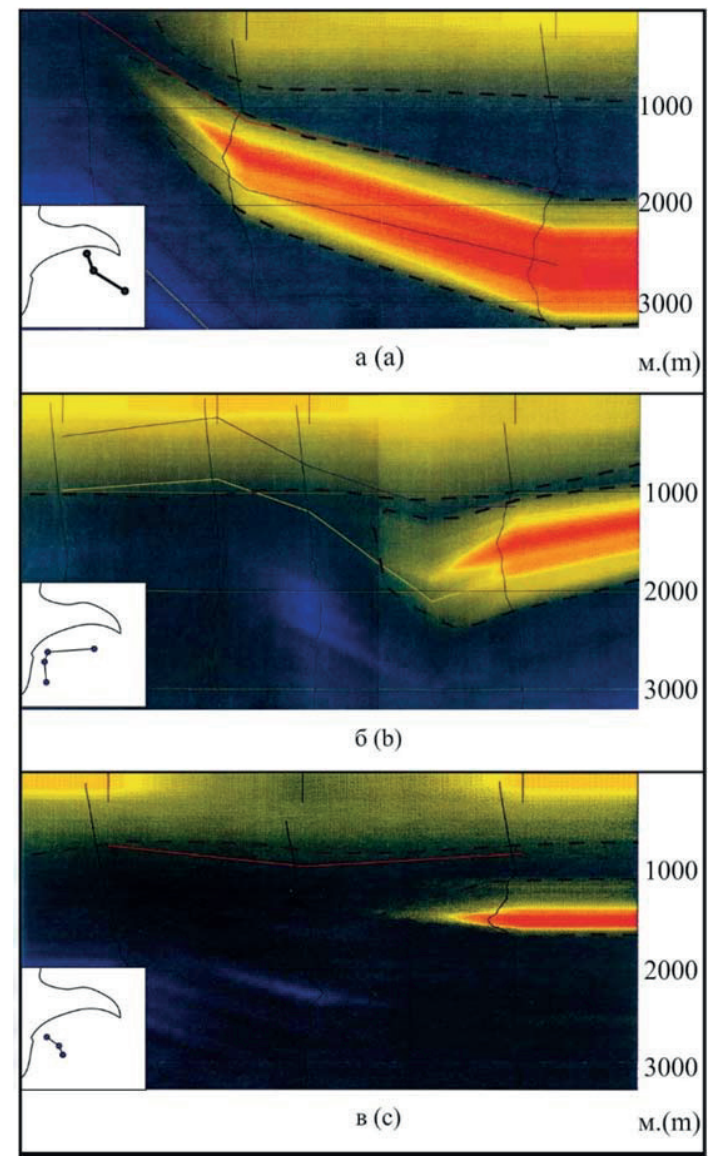

Рис. 8. Интервальная скорость по профилям $(a, 6, в)$

Fig. 8. Interval velocities by profiles $(a, b, c)$ 


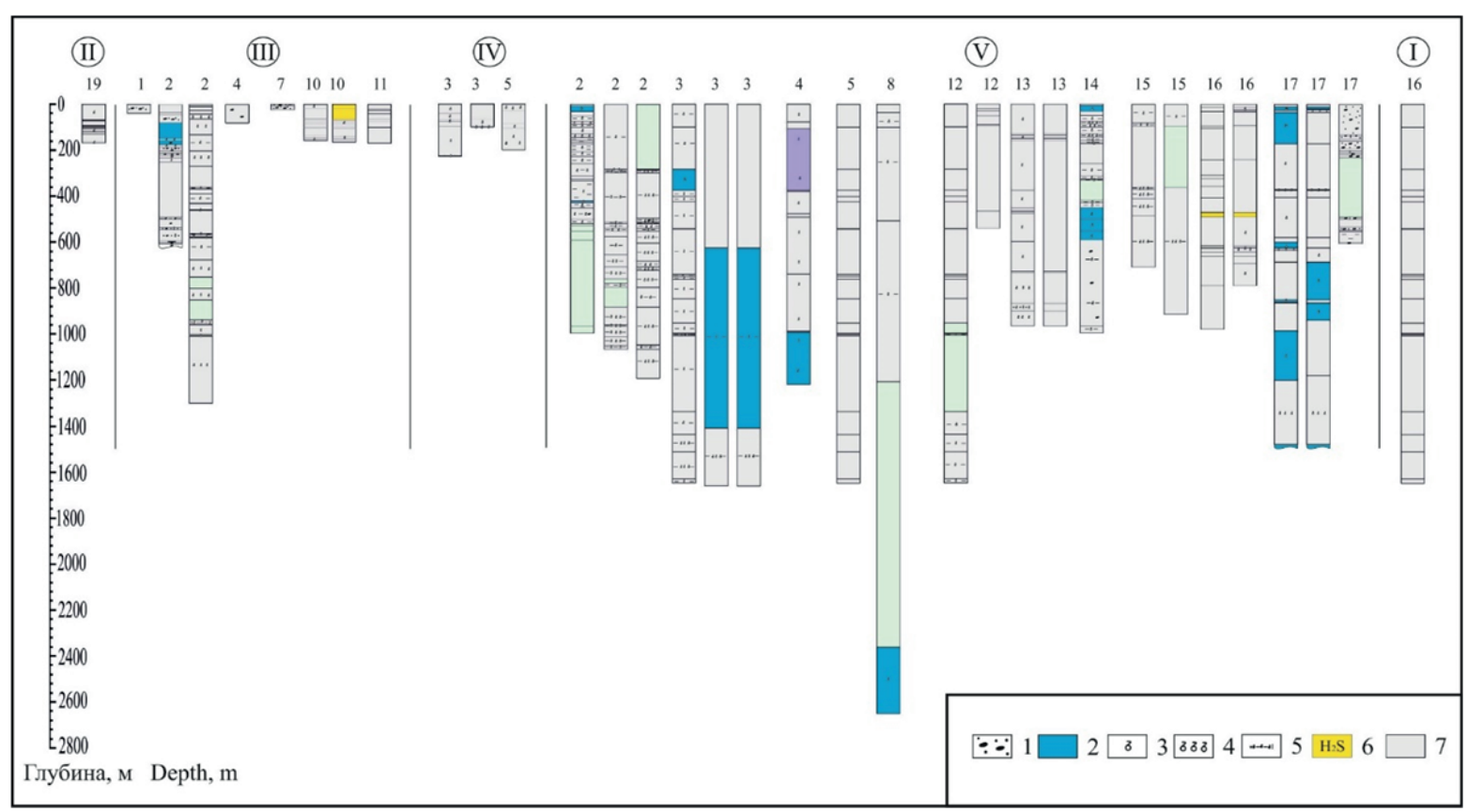

Pис. 9. Газонефтепроявления в пределах Южного Каспия. Условные обозначения:1 - присутствие нефти, 2 - наличие пластовой воды, 3 - наименее интенсивные выходы газа, 4 - наиболее интенсивные выходы газа, 5 - грязевулканическая брекчия, сильно насыщенная газом, 6 - присутствие $\mathrm{H}_{2} \mathrm{~S}, 7$ - преимущественно глинистые отложения

Fig. 9. Gas shows within the South Caspian. Legends: 1 is the oil occurrence, 2 is the strata water occurrence, 3 are the least intensive gas outlets, 4 are the most intensive gas outlets, 5 is the mud-volcanic breccia, highly saturated with gas, 6 is the $\mathrm{H}_{2} \mathrm{~S}$ occurence, 7 are the predominantly clayey deposits

Приведены результаты исследований по 160 сейсмоакустическим профилям основных нефтяных и газовых месторождений Южного Каспия. В результате интерпретации сейсмоакустических данных установлено, что аномалии, характерные для газов, выявлены практически на всех профилях. Интенсивность проявлений газа изменяется как по площади, так и с глубиной. В зонах, прилегающих к глубоководной части Южного Каспия, присутствие аномалий, характерных для газовых зон, увеличивается по сравнению с прибортовыми зонами.

В результате анализа данных по газопроявлениям ВЧР можно сделать следующие выводы:

1. Верхняя часть разреза Южного Каспия сильно обогащена газом, причем интенсивность газо-

\section{СПИСОК ЛИТЕРАТУРЫ}

1. Бык С.Ш., Фомина В.И. Газовые гидраты // Успехи химии. 1968. - T. XXXVII. - № 6. - C. 1097-1135.

2. Carroll J. Natural Gas Hydrates. Second ed. - Boca Raton: CRC Press, 2008. - 248 p.

3. Sloan D.E., Koh C.A. Clathrate Hydrates of Natural Gases. $3^{\text {rd }}$ ed. Boca Raton: CRC Press, 2007. - 721 p.

4. Макагон Ю.Ф. Гидраты природных газов. - М.: Недра, 1974. $208 \mathrm{c.}$

5. Макагон Ю.Ф. Природные газовые гидраты // Российский химический журнал. - 2003. - T. XLVII. - № 3. - С. 70-79. проявлений в нижней части наиболее высокая.

2. Нефтепроявления на структурах Хали, Чилов адасы, Палчыг Пильпиля, Чираг указывают на то, что эти структуры наиболее благоприятны для поисков нефтяных залежей.

3. Пластовая вода зафиксирована в широком интервале глубин.

Полученные выводы дают основание прогнозировать поступление значительных объемов флюидов в верхнюю часть разреза глубоководной части Южного Каспия.

На основе данных термодинамического равновесия рассчитаны объемы зон газогидратов. Исходя из расчетов установлено, что суммарные объемы газа для изучаемой площади отложений составляют $1,15 \cdot 10^{13} \mathrm{M}^{3}$ газа.

6. Макогон Ю.Ф. Газогидраты. История изучения и перспективы освоения // Геология и полезные ископаемые Мирового океана. - 2010. - № 2. - С. 1-17.

7. Панахов Р.А., Адуллаев Э.А., Новрузова С.Г. Газовые гидраты. - Баку: Элм, 2012. -298 с.

8. Kalachand Sain, Harsh Gupta. Gas hydrates in India: Potential and development. - India: Gondwana Research, 2012. - V. 22. P. $645-657$.

9. Muradov Ch.S. The Area of formation of the South Caspian gas hydrates // South-Caspian basin: geology, geophysics, oil and gas content. - Baku: Nafta-Press, 2004. - P. 322-332. 
10. Musakaev N.G., Khasanov M.K., Borodin S.L. The mathematical model of the gas hydrate deposit development in permafrost // International Journal of Heat and Mass Transfer. - 2018. V. 118. - P. 455-461.

11. Şükrü M., Sotirios N.L. Numerical simulations of gas production from Class 1 hydrate and Class 3 hydrate in the Nile Delta of the Mediterranean Sea / Journal of Natural Gas Science and Engineering. - 2018. - V. 52. - P. 248-266.

12. Geophysical characterization of a fine-grained gas hydrate reservoir in the Shenhu area, northern South China Sea: Integration of seismic data and downhole logs / Jiliang Wang, Shiguo Wu, Xiu Kong, Qingping Li, Jianxin Wang, Rong Ding // Marine and Petroleum Geology. - 2018. - V. 92. - P. 895-903.

13. Lorenson Th.D., Collett T.S. National Gas Hydrate Program Expedition 01 offshore India; gas hydrate systems as revealed by hydrocarbon gas geochemistry // Marine and Petroleum Geology. 2018. - V. 92. - P. 477-492.

14. Estimation of seismic velocities and gas hydrate concentrations: a case study from the Shenhu area, northern South China Sea / Jie Liu, Jianzhong Zhang, Fei Ma, Ming Wang, Yunbao Sun // Marine and Petroleum Geology. - 2017. - V. 88. - P. 225-234.

15. High-resolution seismic characterization of the gas and gas hydrate system at Green Canyon 955, Gulf of Mexico, USA/ S.S. Haines, P.E. Hart, T.S. Collett, W. Shedd, M. Frye, P. Weimer, R. Boswell // Marine and Petroleum Geology. - 2017. - V. 82. P. 220-237.

16. Yarveicy H., Ghiasi M.M., Mohammadi A.H. Determination of the gas hydrate formation limits to isenthalpic Joule-Thomson expansions // Chemical Engineering Research and Design. 2018. - V. 132. - P. 208-214.

17. Musakaev N.G., Khasanov M.K., Borodin S.L. The mathematical model of the gas hydrate deposit development in permafrost // International Journal of Heat and Mass Transfer. - 2018. V. 118 . - P. 455-461.

18. Geophysical characterization of a fine-grained gas hydrate reservoir in the Shenhu area, northern South China Sea: Integration of seismic data and downhole logs / Jiliang Wang, Shiguo Wu, Xiu Kong, Qingping Li, Jianxin Wang, Rong Ding // Marine and Petroleum Geology. - 2018. - V. 92 - P. 895-903.

19. Differential fluid migration behaviour and tectonic movement in Lower Silurian and Lower Cambrian shale gas systems in China using isotope geochemistry / Hao Xu, Wen Zhou, Qian Cao, Christopher Xiao, Qiumei Zhou, Haotian Zhang, Yeyu Zhang // Marine and Petroleum Geology. - 2017. - V. 89. - P. 47-57.

20. Seismic evidence and formation mechanism of gas hydrates in the Zhongjiannan Basin, Western margin of the South China Sea / Yintao Lu, Xiwu Luan, Fuliang Lyu, Bin Wang, Zhili Yang, Taotao Yang, Genshun Yao // Marine and Petroleum Geology. 2017. - V. 84. - P. 274-288.

21. Genetic types of gas hydrates in China / Jinxing Dai, Yunyan Ni, Shipeng Huang, Weilong Peng, Wenxue Han, Deyu Gong, Wei Wei // Petroleum Exploration and Development. - 2017. V. 44. - P. 887-898.

22. Hydrocarbon source for oil and gas indication associated with gas hydrate and its significance in the Qilian Mountain permafrost, Qinghai, Northwest China / Bin Cheng, Jianbing Xu, Zhenquan $\mathrm{Lu}$, Yonghong Li, Weichao Wang, Shan Yang, Hu Liu, Ting Wang, Zewen Liao // Marine and Petroleum Geology. - 2017. V. 89. - P. 202-215.

23. Methane source linked to gas hydrate system at hydrate drilling areas of the South China Sea: ore water geochemistry and numerical model constraints / Yu Hu, Min Luo, Linying Chen, Qianyong Liang, Dong Feng, Jun Tao, Shengxiong Yang, Duofu Chen // Journal of Asian Earth Sciences. - 2018. - V. 44. - P. 2-15.

24. Contribution of thermogenic organic matter to the formation of biogenic gas hydrate: Evidence from geochemical and microbial characteristics of hydrate-containing sediments in the Taixinan
Basin, South China Sea / Junli Gong, Xiaoming Sun, Li Xu, Hongfeng Lu // Marine and Petroleum Geology. - 2017. V. 80. - P. 432-449.

25. Макагон Ю.Ф., Хольсти Дж.С. Вискретные кристаллы гидраты // Российский химический журнал. - 2003. - T. XLVII. № 3. - C. 43-48.

26. Геология и геохимия нефти и газа / О.К.Баженова, Ю.К.Бурлин, Б.А.Соколов, В.Е. Хайн / под ред. Б.А. Соколова. - М.: Изд-во МГУ, 2000. - 384 с.

27. Якуцени В.П. Газогидраты - нетрадиционное газовое сырье, их образование, свойства, распространение и газовые ресурсы // Нефтегазовая геология. Теория и практика. - 2013. - Т. 8. № 4. - C. 1-24.

28. Naresh Kumar Thakurl, Sanjeev Rajput. Exploration of Gas Hydrates Geophysical Techniques. - Berlin Heidelberg: Springer-Verlag, 2011. - $281 \mathrm{p}$.

29. Davie M.K., Zatsepina O.Y., Buffet B.A. Methane solubility in marine hydrate environment // Marine Geology. - 2004. V. 203. - P. 117-184.

30. Гинсбург Г.Д., Соловьев В.А. Субмаринные газовые гидраты. М.: ВНИИОкеангеология, 1994. - 194 с.

31. Milkov A.V., Sassen R. Economic geology of offshore gas hydrates accumulations and provinces // Marine and Petroleum geology. - 2002. - V. 19. - P. 1-11.

32. Истомин В.А., Якушев В.С. Газовые гидраты в природных условиях. - М.: Недра, 1992. - 236 с.

33. Kvenvolden K. Methane hydrate - a major reservoir of carbon in the shallow geosphere? // Chemical Geology. - 1988. - V. 71. P. 41-51.

34. The nature, distribution, and origin of gas hydrate in the Chile Triple Junction region / K.M. Brown, N.L. Bangs, P.N. Froelich, K.A. Kvenvolden // Earth and Planetary Science Letters. 1996. - V. 139. - P. 471-483.

35. High-intensity gas seepage causes rafting of shallow gas hydrates in the southeastern Black Sea / T. Pape, A. Bahr, S.A. Klapp, F. Abegg, G. Bohrmann // Earth and Planetary Science Letters. 2011. - V. 307. - P. 35-46.

36. Дмитриевский А.Н., Баланюк И.Е. Газогидраты морей и океанов - источник углеводородов будущего. - М.: 000 «ИРЦ Газпром», 2009. -415 c.

37. Diaconescu C.C., Kieckhefer R.M., Knapp J.H. Geophysical evidence for gas hydrates in the deep water of the South Caspian Basin, Azerbaijan // Marine and Petroleum Geology. - 2001. V. 18. - P. 209-221.

38. Collett T.S., Kvenvolden K.A., Magoon L.B. Characterization of hydrocarbon gas within the stratigraphic interval of gas-hydrate stability of the North Slope of Alaska // Applied Geochemistry. 1990. - V. 55. - P. 279-287.

39. Xəzər dənizinin Abșeron arxipelağı və Bakı arxipelağının şimal hissəsində Azərbaycan sektorunda kəsilişin üst hissəsinin qazlılı̆̆ı və dəniz dibi qaz çıxışlarının (qaz-hidratlar) öyrənilməsi məqsədilə geoloji-geofiziki və qazma məlumatlarının ümumiləşdirilməsi, ARDNS. - Bak1: ARDNS, 2012. - $215 \mathrm{~s}$.

40. Xəzər dənizinin Azərbaycan sektorunda kəsilişin üst hissəsinin qazlılığ1 və dənizdibi qaz çıxışları: təhlil, ümumiləşdirmə və təkliflar / Y.A. Sixəliyev, A.M. Ohmədov, A.Z. Zeynalov, Z.N. Obdiilxakova // Azərbaycan Neft Təsərrüfatı. - 2015. № 5. - S. 9-15.

41. Геология Азербайджана. Нефть и газ / под ред. Ак. А. Али-заде. - Баку: Изд-во Nafta-Press», 2008. - T. VII. - 380 с.

42. Guliyev I.S., Levin L.E., Fedorov D.L. Hydrocarbons potential of the Caspian region (System Analysis). - Baku: Nafta-Press, 2003. $-120 \mathrm{p}$

43. Методология изучения и освоения месторождения Булла-дениз / под ред. Ак.А. Али-заде. - Баку: Национальная Академии Наук Азербайджана, Институт глубинных проблем, 1995. - 138 c. 
44. Geothermal Atlas of Azerbaijan / Ed. by A.A. Ali-Zadeh, S.A. Aliyev. - Baku, Nafta-Press, 2001. 151 p.

45. Seismic character of bottom simulating reflectors: examples from the mid-Norwegian margin / Ch. Berndt, S. Bunz, T. Clayton, J. Mienert, M. Saunders // Marine and Petroleum Geology. 2004. - V. 21. - P. 723-733.

46. Геологические и геохимические условия сохранения углеводородных флюидов в Южно-Каспийском бассейне. - Баку: Институт Геологии Национальной Академии Наук Азербайджана, 2007. -175 с.

47. Гулиев И.С., Дадашев Ф.Г., Полетаев А.В. Изотопы углеводородных газов Азербайджана. - Баку: Nafta-Press, 2013. $107 \mathrm{c}$.
48. Joint Research Program. Phase II. Velocity study of the Baku archipelago. - Baku: IDOGD-UNOCAL, 1994. - 44 p.

49. Подводногрязевулканический тип скоплений газовых гидратов/ Г.Д. Гинсбург, И.С. Грамберг, И.С. Гулиев, Р.А. Гусейнов, А.А. Дадашев, В.Л. Иванов, А.Г. Кротов, Ч.С. Мурадов, В.А. Соловьев, Е.В. Телепнев // Доклады Академии Наук CCCP. -1988 . - T. 300. - № 2. - C. 416-418.

50. Гусейнов Р.А., Дадашев Ф.Г. Углеводородные газы Каспийского моря. - Баку: Нафта-Пресса, 2000. - 128 с.

51. Frye M., Shedd W., Boswell R. Gas hydrate resource potential in the Terrebonne Basin, Northern Gulf of Mexico // Marine and Petroleum geology, - 2011. - V. 34. - P. 1-19.

Поступила 18.09.2018 2.

\section{Информация об авторах}

Полетаев A.B., кандидат геолого-минералогических наук, ведущий научный сотрудник Института нефти и газа Национальной Академии Наук Азербайджана.

Полетаева E.B., доктор философии по наукам о Земле, ведущий научный сотрудник Института нефти и газа Национальной Академии Наук Азербайджана. 
UDC $550.3,550.31,550.46$

\title{
GAS HYDRATES WITHIN AZERBAIJAN SECTOR OF SOUTHERN CASPIAN: THERMODYNAMICS, SEISMOACOUSTICS AND GAS SHOWS
}

\author{
Alexander V. Poletayev', \\ avo1@mail.ru \\ Yelena V. Poletayeva', \\ yelenapv@mail.ru \\ National Academy of Sciences of Azerbaijan,
9, F. Amirov street, Baku, AZ1000, Azerbaijan.
}

Relevance. Geological structure and bathymetry of the seabed of the deep-water part of the Caspian Sea indicate the possibility of formation of significant amounts of gas hydrates. The analysis of the published and unpublished materials on Caspian gas hydrates has shown that basically all works are based only on study of Elm, Bozdag, Absheron gas hydrates accumulation, and thermodynamic factors of the region (without taking into account the actual values of temperature and pressure) in order to determine the possible zone of their accumulation.

The aim of the research is to calculate the volume of hydrocarbon gases of gas hydrates according to thermodynamic data, as well as to study and predict the inflow of hydrocarbon gases into the upper part of the section.

The object of research is deposits of the upper part of the section. Despite the large factual material available in various organizations, the upper part of the section in relation to evaluation of gas content is the least studied and described in the literature zone. This is due to the fact that the main research interval in the Southern Caspian is concentrated in areas with high oil and gas potential. This interval is the productive series and underlying deposits, which are included in the zone of intensive generation of oil and gas. The younger sediments accumulated before the Absheron regiostage, mainly consisting of clay sediments, were of no interest. In many works this zone is described as dissected series of quaternary deposits.

Research methods are based on modelling thermodynamic balance of hydrocarbon gases in order to establish the formation zone of gas hydrates. The authors have used the data of temperatures and pressures measured in the wells of the South Caspian, as well as the data from 160 seismic acoustic profiles, interval velocity sections as well as data on oil and gas occurrences within the shelf zone of the South Caspian.

As a result of thermodynamic equilibrium studies, the volumes of gas hydrate zones were calculated. Based on calculations, it is established that the total gas volumes for the study area are $1,15 \cdot 10^{13} \mathrm{~m}^{3}$ of gas. As a result of interpretation of seismoacoustic data, it is established that the intensity of gas manifestations varies both in area and depth. In the zones adjacent to the deep-water part of the South Caspian, the presence of anomalies characteristic of gas zones increases in comparison with the instrument zones. Based on the analysis of the data on gas manifestations, it can be concluded that the upper part of the section of the South Caspian is strongly enriched with gas, and the intensity of gas manifestations in the lower part is the highest. Oil shows within Khali, Chilov adasi, Palchig Pilpil, Chirag structures indicate that these structures are more favorable for the search for oil deposits. The reservoir water is fixed in a wide range of depths. The obtained results enable to predict the receipt of significant volumes of fluids in the upper part of the section of the deep-water part of the South Caspian.

Key words:

Gas hydrates, seismoacoustic profiles, estimation, gas, South Caspian, oil and gas fields.

\section{REFERENCES}

1. Byk S.Sh., Fomina V.I. Gazovyegidraty [Gashydrates]. Uspekhi Khimii, vol. XXXVII, 1968, no. 6, pp. 1097-1135.

2. Carroll J. Natural Gas Hydrates. Second ed. Boca Raton, CRC Press, 2008. $248 \mathrm{p}$.

3. Sloan D.E., Koh C.A. Clathrate Hydrates of Natural Gases. Third ed. Boca Raton, CRC Press, 2007. 721 p.

4. Makagon Yu.F. Gidraty prirodnykh gazov [Gas hydrates of natural gases]. Moscow, Nedra Publ., 1974. 208 p.

5. Makagon Yu.F. Prirodnye gazovye gidraty [Natural gashydrates]. Rossiyskiy khimicheskiy zhurnal, 2003, vol. XLVII, no. 3, pp. $70-79$.

6. Makogon Yu.F. Gas hydrates. History of study and perspective of development. Geology and mineral resources of the world ocean, 2010, no. 2, pp. 1-17. In Rus.

7. Panakhov R.A., Adullaev E.A., Novruzova S.G. Gazovyegidraty [Gashydrates]. Baku, Elm, 2012. 298 p.

8. KalachandS ain, Harsh Gupta. Gashydrates in India: Potential and development. Gondwana Research, 2012, vol. 22, pp. 645-657.

9. Muradov Ch.S. The Area of formation of the South Caspian gas hydrates. South-Caspian basin: geology, geophysics, oil and gas content. Baku, Nafta-Press, 2004, pp. 322-332.
10. Musakaev N.G., Khasanov M.K., Borodin S.L., The mathematical model of the gas hydrate deposit development in permafrost. International Journal of Heat and Mass Transfer, 2018, vol. 118, pp. $455-461$.

11. Şükrü M., Sotirios N.L. Numerical simulations of gas production from Class 1 hydrate and Class 3 hydrate in the Nile Delta of the Mediterranean Sea. Journal of Natural Gas Science and Engineering, 2018, vol. 52, pp. 248-266.

12. Jiliang Wang, Shiguo Wu, Xiu Kong, Qingping Li, Jianxin Wang, Rong Ding. Geophysical characterization of a fine-grained gas hydrate reservoir in the Shenhu area, northern South China Sea: Integration of seismic data and downhole logs. Marine and Petroleum Geology, 2018, vol. 92, pp. 895-903.

13. Lorenson T.D., Collett T.S. National Gas Hydrate Program Expedition 01 offshore India; gas hydrate systems as revealed by hydrocarbon gas geochemistry. Marine and Petroleum Geology, 2018, vol. 92, pp. 477-492.

14. Jie Liu, Jianzhong Zhang, Fei Ma, Ming Wang, Yunbao Sun. Estimation of seismic velocities and gas hydrate concentrations: a case study from the Shenhu area, northern South China Sea. $M a$ rine and Petroleum Geology, 2017, vol. 88, pp. 225-234.

15. Haines S.S., Hart P.E., Collett T.S., Shedd W., Frye M., Weimer P., Boswell R. High-resolution seismic characterization of 
the gas and gas hydrate system at Green Canyon 955, Gulf of Mexico, USA. Marine and Petroleum Geology, 2017, vol. 82, pp. 220-237.

16. Yarveicy H., Ghiasi M.M., Mohammadi A.H. Determination of the gas hydrate formation limits to isenthalpic Joule-Thomson expansions. Chemical Engineering Research and Design, 2018, vol. 132, pp. 208-214.

17. Musakaev N.G., Khasanov M.K., Borodin S.L. The mathematical model of the gas hydrate deposit development in permafrost. In ternational Journal of Heat and Mass Transfer, 2018, vol. 118, pp. $455-461$.

18. Jiliang Wang, Shiguo Wu, Xiu Kong, Qingping Li, Jianxin Wang, Rong Ding. Geophysical characterization of a fine-grained gas hydrate reservoir in the Shenhu area, northern South China Sea: Integration of seismic data and downhole logs. Marine and Petroleum Geology, 2018, vol. 92, pp. 895-903.

19. Hao Xu, Wen Zhou, Qian Cao, Christopher Xiao, Qiumei Zhou, Haotian Zhang, Yeyu Zhang.Differential fluid migration behaviour and tectonic movement in Lower Silurian and Lower Cambrian shale gas systems in China using isotope geochemistry. Mar. Pet.Geol., 2017, vol. 89, pp. 47-57.

20. Yintao Lu, Xiwu Luan, FuliangLyu, Bin Wang, Zhili Yang, Taotao Yang, Genshun Yao. Seismic evidence and formation mechanism of gas hydrates in the Zhongjiannan Basin, Western margin of the South China Sea. Marine and Petroleum Geology, 2017, vol. 84, pp. 2740-288.

21. Jinxing Dai, Yunyan Ni, Shipeng Huang, Weilong Peng, Wenxue Han, Deyu Gong, Wei Wei. Genetic types of gas hydrates in China. Petroleum Exploration and Development, 2017, vol. 44, pp. 887-898.

22. Bin Cheng, Jianbing $\mathrm{Xu}$, Zhenquan Lu, Yonghong Li, Weichao Wang, Shan Yang, Hu Liu, Ting Wang, Zewen Liao. Hydrocarbon source for oil and gas indication associated with gas hydrate and its significance in the Qilian Mountain permafrost, Qinghai, Northwest China. Mar. Pet. Geol., 2017, vol. 89, pp. 202-215.

23. Yu Hu, Min Luo, Linying Chen, Qianyong Liang, Dong Feng, Jun Tao, Shengxiong Yang, Duofu Chen. Methane source linked to gas hydrate system at hydrate drilling areas of the South China Sea: orewater geochemistry and numerical model constraints. Journal of Asian Earth Sciences, 2018, vol. 44, pp. 2-15.

24. Junli Gong, Xiaoming Sun, Li Xu, Hongfeng Lu. Contribution of thermogenic organic matter to the formation of biogenic gas hydrate: Evidence from geochemical and microbial characteristics of hydrate-containing sediments in the Taixinan Basin, South China Sea. Marine and Petroleum Geology, 2017, vol. 80, pp. 432-449.

25. Makagon Yu.F., Kholsti Dzh. S. Viskret crystal gyrates. Russian chemical journal, 2003, vol. XLVII, no. 3, pp. 43-48. In Rus.

26. Bazhenova 0.K., Burlin Yu.K., Sokolov B.A., Khayn V.E. Geologiya $i$ geokhimiya nefti i gaza [Geology and geochemistry of oil and gas]. Ed. By B.A. Sokolov. Moscow, MGU Press, 2000. 384 p.

27. Yakutseni V.P. Gas hydrates - alternative gas source, their formation, property, location and gas potential. Petroleum geology. Theory and practices, 2013, vol. 8, no. 4, pp. 1-24. In Rus.

28. Naresh Kumar Thakur, Sanjeev Rajput. Exploration of Gas Hydrates Geophysical Techniques. Berlin Heidelberg, Springer-Verlag, 2011. $281 \mathrm{p}$

29. Davie M.K., Zatsepina O.Y., Buffet B.A. Methane solubility in marine hydrate environment. Marine Geology, 2004, vol. 203, pp. 117-184.

30. Ginsburg G.D., Solovev V.A. Submarinnye gazovye gidraty [Submarine gas hydrates]. Moscow, VNIIOkeangeologiya Publ., 1994. $193 \mathrm{p}$.

31. Milkov A.V., Sassen R. Economic geology of offshore gas hydrates accumulations and provinces. Marine and Petroleum geology, 2002, no. 19, pp. 1-11.

32. Istomin V.A., Yakushev V.S. Gazovye gidraty v prirodnykh usloviyakh [Gas hydrate in natural conditions]. Moscow, Nedra Publ., 1992. $236 \mathrm{p}$.
33. Kvenvolden K. Methane hydrate - a major reservoir of carbon in the shallow geosphere? Chemical Geology, 1988, vol. 71, pp. 41-51.

34. Brown KM., Bangs N.L., Froelich P.N., Kvenvolden K.A. The nature, distribution, and origin of gas hydrate in the Chile Triple Junction region. Earth and Planetary Science Letters, 1996, vol. 139, pp. 47l-483.

35. Pape Th., Bahr A., Klapp S.A., Abegg F., Bohrmann G. High-intensity gas seepage causes rafting of shallow gas hydrates in the southeastern Black Sea. Earth and Planetary Science Letters, 2011, vol. 307, pp. 35-46.

36. Dmitrievskiy A.N., Balanyuk I.E. Gazogidraty morey i okeanov istochnik uglevodorodov budushchego [Gas hydrates of the sea and ocean - hydrocarbon future source]. Moscow, IRTs GAZPROM LTD, 2009. $415 \mathrm{p}$.

37. Diaconescu C.C., Kieckhefer R.M., Knapp J.H. Geophysical evidence for gas hydrates in the deep water of the South Caspian Basin, Azerbaijan. Marine and Petroleum Geology, 2001, vol. 18, pp. 209-221.

38. Collett T.S., Kvenvolden K.A., Magoon L.B. Characterization of hydrocarbon gas within the stratigraphic interval of gas-hydrate stability of the North Slope of Alaska. Applied Geochemistry, 1990, vol. 55, pp. 279-287.

39. Xəzər dənizinin Abșeron arxipela ğ və Bakı arxipelağının șimal hissəsindəAzərbaycan sektorunda kəsilişin üst hissəsinin qazlılı̆̆1 və dəniz dibi qaz çıxışlarının (qaz-hidratlar) öyrənilməsi məqsədila geoloji-geofiziki və qazma məlumatlarının ümumiləşdirilməsi [Gas hearing capacity in upper part of section and sea bottom gas shows (gas hydrates) in Absheron archipelago and northern part of Baku archipelago of Azerbaijan sector Caspian Sea with aims geological, geophysical and drilling data collection]. Baku, SOCAR Publ., 2012. 215 p. In Azeri.

40. Ş1xəliyev Y.A., Әhmədov A.M., Zeynalov A.Z., Әbdiilxakova Z.N. Xəzər dənizinin Azərbaycan sektorunda kəsilişin üst hissəsinin qazlılığ1 və dənizdibi qaz çıxışları: təhlil, ümumiləşdirmə və təkliflər [Gas hearing capacity in upper portion of section and sea bottom gas shows in Azerbaijan sector of Caspian Sea: analysis, summary and proposals]. Geologiya va geofizika, 2015, vol. 5, pp. 9-15. In Azeri.

41. Geologiya Azerbaydzhana [Geology of Azerbaijan]. Vol. VII. Neftigaz [Vol. VII. Oil and gas]. Ed. by A.A. Ali-Zadeh. Baku, NaftaPress Publ. house, 2008. 380 p.

42. Guliyev I.S., Levin L.E., Fedorov D.L. Hydrocarbons Potential of the Caspian Region (System Analysis). Baku, Nafta-Press, $2003.120 \mathrm{p}$

43. Metodologiya izucheniya i osvoeniya mestorozhdeniya Bulla-Deniz [Methodology of study and developing the Bulla-Deniz field, the National Academy of Sciences of Azerbaijan]. Ed. by A.A. AliZadeh. Baku, National Academy of Sciences of Azerbaijan, the Institute of Deep Problems, 1995. 138 p.

44. Geothermal Atlas of Azerbaijan. Ed. by A.A. Ali-Zadeh, S.A. Aliyev. Baku, Nafta-Press 2001, $151 \mathrm{p}$.

45. Berndt Ch., Bunz S., Clayton T., Mienert J., Saunders M. Seismic character of bottom simulating reflectors: examples from the mid-Norwegian margin. Marine and Petroleum Geology, 2004, vol. 21, pp. 723-733.

46. Geologicheskie i geokhimicheskie usloviya sokhraneniya uglevodorodnykh flyuidov $v$ Yuzhno-Kaspiyskom Basseyne [Geological and geochemical conditions for conservation of hydrocarbon fluids in the South Caspian basin]. Baku, Institut Geologii Natsionalnoy Akademii Nauk Azerbaydzhana-SIW, Geology Institute of National Academy of Sciences Azerbaijan, 2007. 175 p.

47. Guliev I.S., Dadashev F.G. Poletaev A.V. Izotopy uglevodorodnykh gazov Azerbaydzhana [Isotopes of hydrocarbon gases of Azerbaijan]. Baku, Nafta-Press Publ. house, 2013. 107 p.

48. Joint Research Program. Phase II. Velocity study of the Baku archipelago. Baku, IDOGD-UNOCAL, 1994. 44 p. 
49. Ginsburg G.D., Gramberg I.S., Guliev I.S., Guseynov R.A., Dadashev A.A., Ivanov V.L., Krotov A.G., Muradov Ch.S., Solovev V.A., Telepnev E.V. Podvodnogryazevulkanicheskiy tip skopleniy gazovykh gidratov [Subsea mud volcanoes type of the gas hydrate fields]. Doklady Akademii Nauk SSSR, 1988, vol. 300, no. 2, pp. 416-418.

50. Guseynov R.A., Dadashev F.G. Uglevodorodnye gazy kaspiyskogo morya [Hydrocarbon gases of the Caspian Sea]. Baku, Nafta-Press Publ. house, 2000.128 p.
51. Frye M., Shedd W., Boswell R. Gas hydrate resource potential in the Terrebonne Basin, Northern Gulf of Mexico. Marine and Petroleum geology, 2011, vol. 34, pp. 1-19.

Received: 18 September 2018.

\section{Ineormation about the authors}

Alexander V. Poletayev, Cand. Sc., leading researcher Oil and Gas Institute of National Academy of Sciences of Azerbaijan.

Yelena V. Poletayeva, Dr. Sc., leading researcher Oil and Gas Institute of National Academy of Sciences of Azerbaijan. 